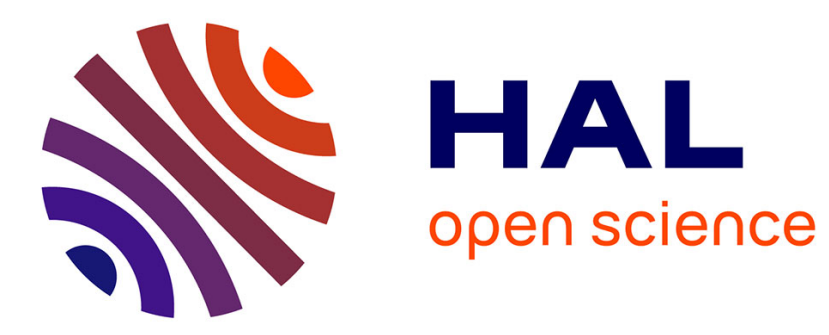

\title{
Unit Cell for Reflectarrays Operating With Independent Dual Circular Polarizations
}

\author{
Simon Mener, Raphaël Gillard, Ronan Sauleau, Cécile Cheymol, Patrick
}

Potier

\section{> To cite this version:}

Simon Mener, Raphaël Gillard, Ronan Sauleau, Cécile Cheymol, Patrick Potier. Unit Cell for Reflectarrays Operating With Independent Dual Circular Polarizations. IEEE Antennas and Wireless Propagation Letters, 2014, 13, pp.1176 - 1179. hal-01121838

\section{HAL Id: hal-01121838 \\ https://hal.science/hal-01121838}

Submitted on 4 Mar 2015

HAL is a multi-disciplinary open access archive for the deposit and dissemination of scientific research documents, whether they are published or not. The documents may come from teaching and research institutions in France or abroad, or from public or private research centers.
L'archive ouverte pluridisciplinaire HAL, est destinée au dépôt et à la diffusion de documents scientifiques de niveau recherche, publiés ou non, émanant des établissements d'enseignement et de recherche français ou étrangers, des laboratoires publics ou privés. 


\title{
Unit-Cell for Reflectarrays Operating with Independent Dual-Circular Polarizations
}

\author{
Simon Mener, Raphael Gillard, Ronan Sauleau, Senior Member, IEEE, Cecile Cheymol, Patrick Potier
}

\begin{abstract}
A unit-cell for dual-circularly polarized (CP) reflectarrays illuminated by a dual $\mathrm{CP}$ primary feed is designed and validated experimentally around $8.5 \mathrm{GHz}$. It is composed of two layers reflecting independently and simultaneously the two incident circular polarizations. The first layer is a circular polarization selective surface (CPSS) based on an enhanced version of the original Pierrot's cell with multiple wires bent in a crank-like shape. The second layer is made of dipoles printed on a grounded substrate; it is used to reflect the incident RHCP wave transmitted through the CPSS with a 2-bit phase resolution. The paper demonstrates that the sole association of both layers is not sufficient to reach the expected behavior. An additional optimization step is required to cancel out uncontrolled reflections and improve isolation between both polarizations. The simulated and measured characteristics are in good agreement for the two circular polarizations.
\end{abstract}

Index Terms - Dual-circular polarization, Circular polarization selective surface, reflectarray, unit-cell.

\section{INTRODUCTION}

$\mathrm{R}$ EFLECTARRAYS are very attractive for a number of applications [1], including Earth observation or satellite communications. In this context, circular polarization (CP) is usually preferred to prevent from loss due to polarization misalignment and increase the transmission data rate. Many passive unit-cells have already been proposed for circularlypolarized reflectarrays. They use either a linearly-polarized incident wave [2]-[5] or a circularly-polarized one [6]-[9]. Excellent performance has been reported for single circular polarization in $X$-band by using multiple-resonance broadband elements (bandwidth of $14 \%$ in [10] and even up to $18 \%$ in [11]).

However, dual circular polarization has only been demonstrated by using a different frequency band for LHCP and RHCP [12]-[15]. One idea consists in designing a unit-cell with two different layers, each of them operating in one frequency band. Obviously, in such configurations, the upper layer should be transparent in the other frequency band. On the other hand, a few reconfigurable configurations in $\mathrm{CP}$ have also been reported by using a CP incident wave [15]-[18].

This work was supported in part by the Centre National d'Etudes Spatiales (CNES) and in part by the Direction Générale de l'Armement (DGA).

S. Mener and R. Gillard are with the Institute of Electronics and Telecommunications of Rennes, INSA, UMR CNRS 6164, 35708 Rennes (email : simon.mener@insa-rennes.fr).

R. Sauleau is with the Institute of Electronics and Telecommunications of Rennes, University of Rennes 1, UMR CNRS 6164, 35042 Rennes (ronan.sauleau@univ-rennes1.fr).

C. Cheymol is with the French space agency CNES, 31401, Toulouse CEDEX 9, France (cecile.cheymol@cnes.fr).

P. Potier is with the DGA Maîtrise de l'information, BP 57419, 35174, Bruz CEDEX, France (patrick.potier@dga.defense.gouv.fr).
Once again, the problem of dual circular polarization with independent control at the same frequency has not been addressed.

Therefore the main objective of this work is to propose a dual-CP unit-cell able to produce two independent phase responses in the same frequency band so as to control separately the two incident circular polarizations. To our best knowledge, it is the first time this is achieved.

The proposed unit-cell has been designed in the perspective of providing reconfiguration capabilities in a future active version. Consequently, although the demonstration is only given with frozen states, the proposed layout includes the parasitic elements that would be needed for a $2 \times 2$-bit active cell (4 phase states per polarization).

Basically, the studied cell is an extension of the circular polarization selective surface (CPSS) phase-shifting unit-cell we studied in [19]. Here, it is combined with a quite classical CP unit-cell to control the polarization traveling through the CPSS. However, combining both layers is not as straightforward as one could imagine, mainly due to idle reflecting elements that are responsible for imperfectness in the individual response of each layer.

This paper is organized as follows. The operating principle is discussed in Section II. The design and the measured performance of the second layer are described in Section III. A. The experimental validation of the whole unit-cell is provided in Section III.B. Finally, conclusions are drawn in Section IV.

\section{PRINCIPLE}

A unit-cell based on a CPSS has been described in [19]-[21] as an attractive building block for dual-CP reflectarrays (Fig. 1a). The first layer (layer 1 in Fig. 1) is described in detail in [19] and is a circular Left-Hand CPSS (LH-CPSS) reflecting the incident LHCP with a controllable reflection phase. The incident RHCP is transmitted to the second layer (layer 2 in Fig. 1) that reflects it with an independent controllable reflection phase shift. As layer 2 operates in single polarization, it only requires standard CP unit-cells (e.g. [22]).

The LH-CPSS has been validated experimentally in [19] and is derived from the Pierrot's cell [23]. It consists of a $1 \lambda$-long resonant wire, folded into 3 segments in a crank-like shape. The

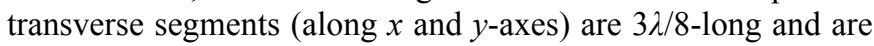
connected by a $\lambda / 4$ central vertical segment (along $z$-axis). As described in [7], four different configurations of the horizontal segments with appropriate rotation angles are needed to achieve four phase states. In a future version of the active cell, switches (e.g. MEMS [15] or p.i.n. diode [24]) will be used to connect or disconnect the metallic segments forming the resonant crank. 


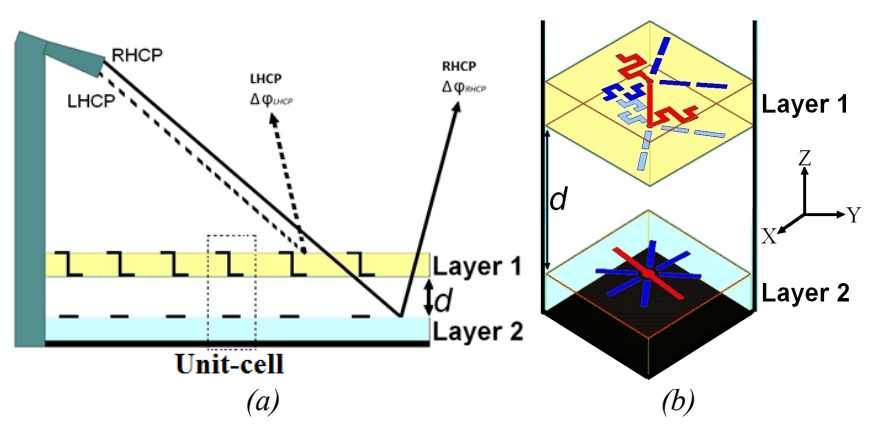

Fig. 1. Independent control of both incident circular polarizations. (a) Schematic representation of the reflectarray (b) Proposed unit-cell.

This LH-CPSS provides a high isolation $(20 \mathrm{~dB}$ at $8.5 \mathrm{GHz})$ between the two incident circular polarizations and almost a 2bit phase resolution [19]-[21].

As done in [25], the complete unit-cell is embedded in a square metallic waveguide to reduce mutual coupling between neighboring unit-cells and because Pierrot's cell is very sensitive to incidence angle [26]. For the proposed cell, simulations (not shown for brevity) have established that the incidence angle should not exceed $20^{\circ}$. This limits the applicability of this solution to reflectarrays using either a large $F / D$ ratio or a facetted configuration [27]. Note that possible improvements have been reported recently to increase the robustness of such a cell to incidence angle [28].

Here, we focus our attention on the whole unit-cell. In particular we show that a convenient co-design of both layers and an optimization of the distance $d$ (Fig. 1a) separating them is required to obtain simultaneously i) a good isolation between both polarizations, and ii) a 2-bit phase resolution in LHCP and RHCP.

\section{DUAL-CIRCULARLY POLARIZED UNIT-CELL}

\section{A. Description of the second layer and experimental characterization}

As illustrated in Fig. 1b, this second layer (based on [22]) reflects the incident RHCP wave transmitted through the first layer (LH-CPSS). The rotation principle [29] has been implemented here around $8.5 \mathrm{GHz}$ : 4 dipole configurations with an appropriate rotation angle have been defined to reflect the incident RHCP wave with a nearly 2-bit phase resolution. Here the dipoles are printed on a thin RT/Duroid 6002 substrates $\left(\varepsilon_{r}=2.94, \tan \delta=0.0012\right)$ glued with a $3 \mathrm{M}$ bonding film on a $6.5 \mathrm{~mm}$-thick low-permittivity foam layer $\left(\varepsilon_{r}=1.066\right.$, $\tan \delta=0.0015$, Fig. 2a).

Four breadboards, one per phase state, have been manufactured. Fig. 2 shows the fabricated prototype for State 2. The reflected phase, measured in RHCP $\left(\Gamma_{\mathrm{R}-\mathrm{R}}\right)$, is plotted in Fig. 3. These results demonstrate that four $90^{\circ}$-spaced phase states are obtained with almost the same frequency dispersion. Moreover, the RHCP incident wave is correctly reflected with insertion loss lower than $1 \mathrm{~dB}$ between $8.2 \mathrm{GHz}$ and $8.8 \mathrm{GHz}$ (not shown). Note that the measurement procedure to extract the $S$-matrix of the cell is the same as for the LH-CPSS cell, explained in [19].

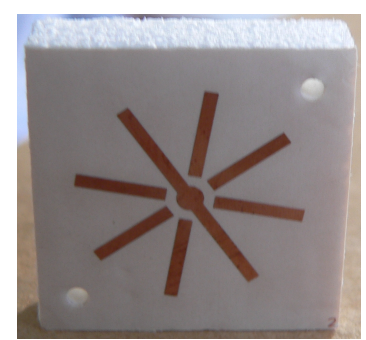

Fig. 2. Fabricated prototype (State 2).

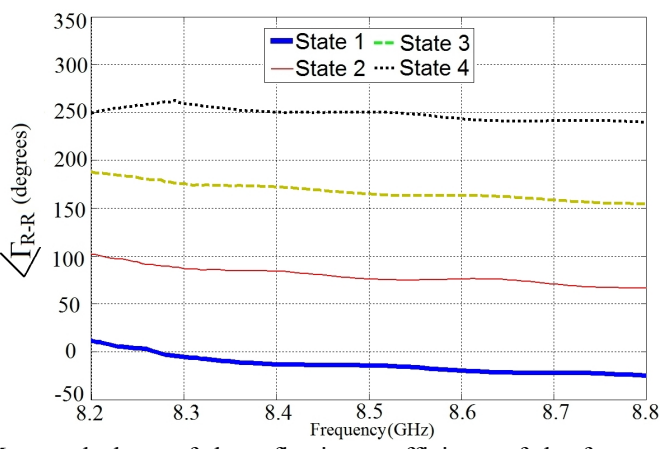

Fig. 3. Measured phase of the reflection coefficients of the four states for a RHCP incident wave.

\section{B. Experimental validation of the dual circularly polarized unit-cell}

Layers 1 and 2 are now combined to form a complete unitcell for dual-CP reflectarray applications with independent control of each polarization. The sixteen possible configurations and the expected reflected phases in LHCP and in RHCP are summarized in Table I.

TABLE I

CHARACTERISTICS OF THE 16 CONFIGURATIONS OF THE WHOLE UNIT-CELL

\begin{tabular}{|c|c|c|c|c|}
\hline Configuration & $\begin{array}{c}\text { Layer } 1 \\
\text { (LH-CPSS) } \\
\text { in state } i \\
(1<i<4)\end{array}$ & $\begin{array}{c}\begin{array}{c}\text { Layer } 2 \\
\text { (dipole) }\end{array} \\
\text { in state } j \\
(1<j<4)\end{array}$ & $\begin{array}{l}\text { Expected } \\
\text { LHCP } \\
\text { reflected } \\
\text { phase at } \\
\text { resonance }\end{array}$ & $\begin{array}{l}\text { Expected } \\
\text { RHCP } \\
\text { reflected } \\
\text { phase at } \\
\text { resonance }\end{array}$ \\
\hline 1 & State 1 & State 1 & $0^{\circ}$ & $0^{\circ}$ \\
\hline 2 & State 1 & State 2 & $0^{\circ}$ & $90^{\circ}$ \\
\hline 3 & State 1 & State 3 & $0^{\circ}$ & $180^{\circ}$ \\
\hline 4 & State 1 & State 4 & $0^{\circ}$ & $270^{\circ}$ \\
\hline 5 & State 2 & State 1 & $90^{\circ}$ & $0^{\circ}$ \\
\hline 6 & State 2 & State 2 & $90^{\circ}$ & $90^{\circ}$ \\
\hline 7 & State 2 & State 3 & $90^{\circ}$ & $180^{\circ}$ \\
\hline 8 & State 2 & State 4 & $90^{\circ}$ & $270^{\circ}$ \\
\hline 9 & State 3 & State 1 & $180^{\circ}$ & $0^{\circ}$ \\
\hline 10 & State 3 & State 2 & $180^{\circ}$ & $90^{\circ}$ \\
\hline 11 & State 3 & State 3 & $180^{\circ}$ & $180^{\circ}$ \\
\hline 12 & State 3 & State 4 & $180^{\circ}$ & $270^{\circ}$ \\
\hline 13 & State 4 & State 1 & $270^{\circ}$ & $0^{\circ}$ \\
\hline 14 & State 4 & State 2 & $270^{\circ}$ & $90^{\circ}$ \\
\hline 15 & State 4 & State 3 & $270^{\circ}$ & $180^{\circ}$ \\
\hline 16 & State 4 & State 4 & $270^{\circ}$ & $270^{\circ}$ \\
\hline
\end{tabular}

From [19], it can be seen that polarization isolation of the LH-CPSS cell, although very good, is not perfect: approximately $10 \%$ of the power is not properly handled (the 
isolation coefficients $\Gamma_{\mathrm{R}-\mathrm{L}}, \Gamma_{\mathrm{L}-\mathrm{R}}, T_{\mathrm{R}-\mathrm{L}}$ and $T_{\mathrm{L}-\mathrm{R}}$ equal $20 \mathrm{~dB}$ at 8.5 $\mathrm{GHz}$ ). As a result, parasitic uncontrolled waves with inappropriate polarization may arise, thus disturbing the ideal operation described in Fig. 1a. Fig. 4 represents the bandwidth of the whole unit-cell for several values of $d$ which is the more prominent degree of freedom to minimize undesirable wave recombination. The optimal distance $d$ is $20 \mathrm{~mm}$. Fig. 5 shows a $3 \mathrm{D}$ view of the fabricated prototype in configuration 5 (Table I). The amplitudes of the measured reflection coefficients for the sixteen configurations are represented in LHCP and RHCP in Figs. $6 \mathrm{a}$ and $6 \mathrm{~b}$, respectively. This figure demonstrates that the complete unit-cell exhibits attractive performance, with a $3.8 \%$ fractional bandwidth $(0.32-\mathrm{GHz}$ from 8.22 to $8.54 \mathrm{GHz})$ and insertion loss lower than $1 \mathrm{~dB}$ in both polarizations. As shown in Fig. 6a, the bandwidth is limited by resonances appearing for a few configurations (typically at $8.21 \mathrm{GHz}$ for configuration 13 and at $8.58 \mathrm{GHz}$ for configuration 12). These resonances are due to out-of-phase recombination of controlled and uncontrolled waves, as explained above.

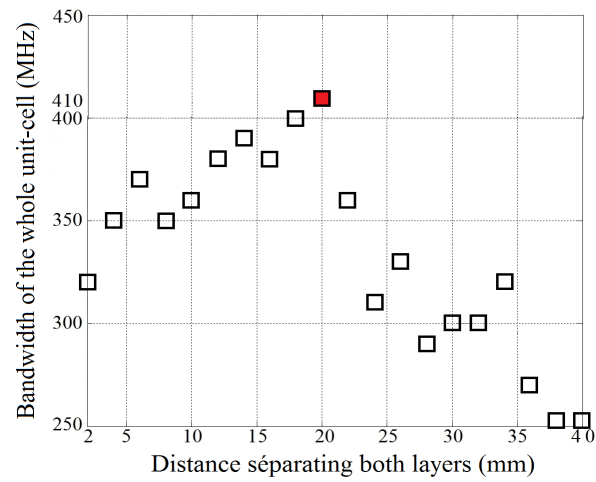

Fig. 4. Bandwidth of the whole unit-cell versus $d$.

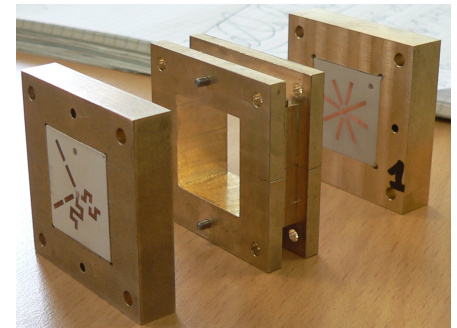

Fig. 5. One of the sixteen configuration of the complete unit-cell (here configuration 5).

The measured reflected phases of the unit-cell are plotted in Fig. 7a (LHCP) and Fig. 7b (RHCP). Four $90^{\circ}$-spaced phase responses are obtained in reflection with almost the same frequency dispersion in LHCP and in RHCP, respectively for the four states of the first and second layers. Moreover, the phase states in one polarization do not depend on the phase states of the other polarization, as desired.

The reflection coefficients in cross-polarization have been measured and are given for the two most critical configurations (configurations 12 and 13). They are represented in Fig. 8 as a function of frequency. They are better than $15 \mathrm{~dB}$ between 8.24 and $8.53 \mathrm{GHz}$. For all other configurations, the polarization isolation is better than $20 \mathrm{~dB}$ in the same frequency range.
The simulated and measured equivalent bit numbers are better than 1.92 bits over the [8.2-8.55 GHz] range for both incident polarizations.

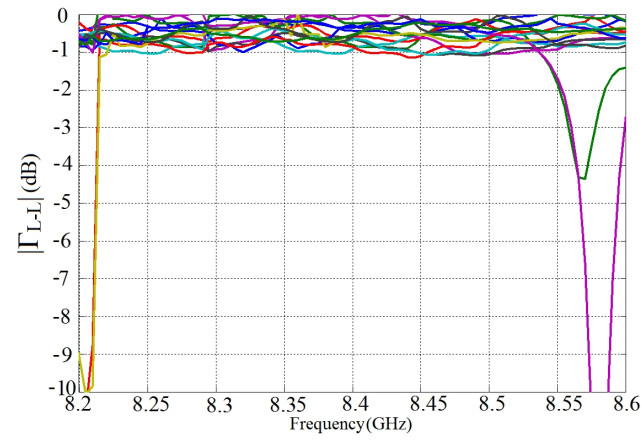

(a)

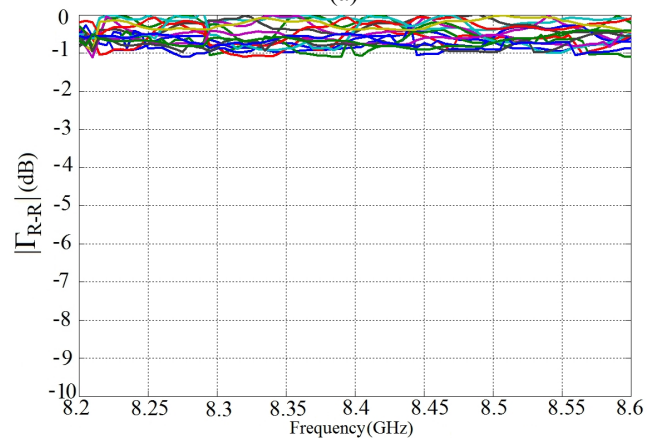

(b)

Fig. 6. Measured magnitude of the reflection coefficients for the 16 configurations of the complete unit-cell. (a) LHCP. (b) RHCP.

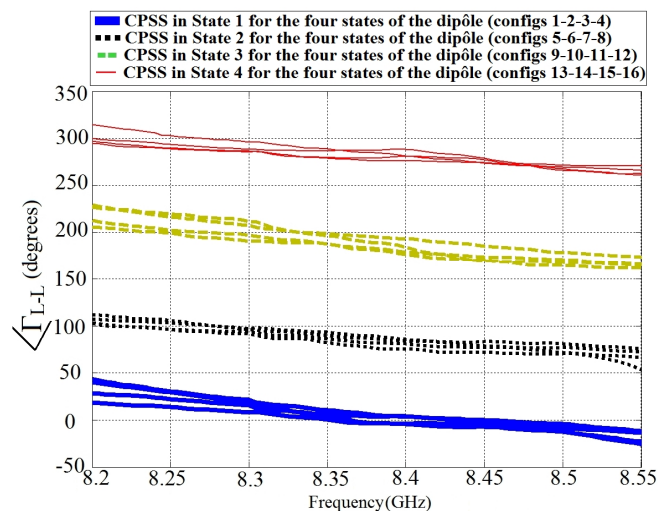

(a)

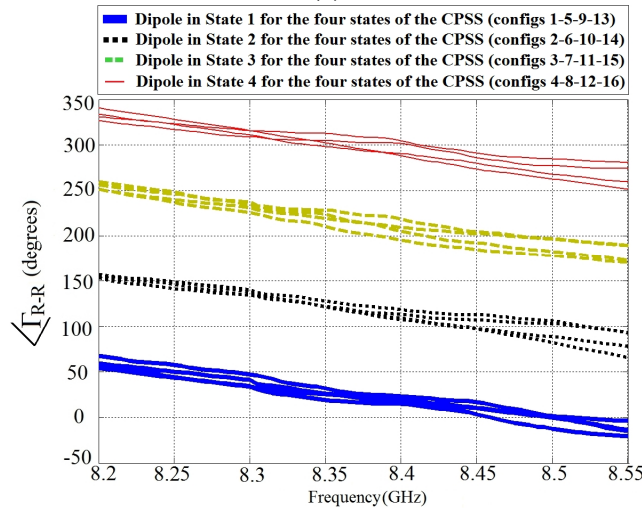

(b)

Fig. 7. Measured phase of the reflection coefficients for the 16 configurations of the complete unit-cell. (a) LHCP. (b) RHCP. 


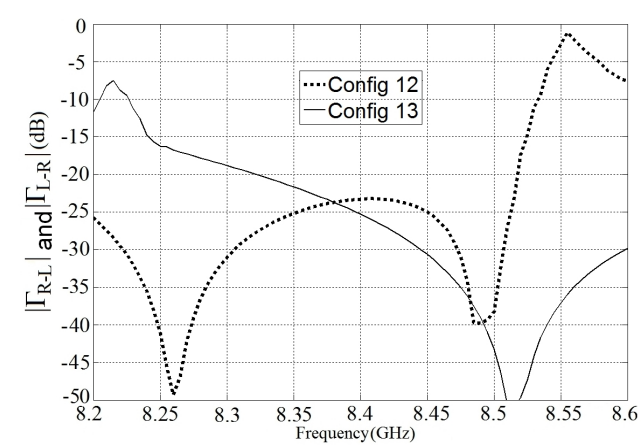

Fig. 8. Measured reflection coefficients in cross-polarization for LHCP and RHCP illumination (most critical cases).

\section{CONCLUSION}

A unit-cell for dual-CP reflectarrays has been introduced for the first time with the unique capability to reflect independently and simultaneously the two incident circular polarizations at the same frequency. The proposed design has been optimized in X-band by a convenient co-design of both layers (LH-CPSS and the dipoles) so as to obtain a high isolation between both incident polarizations. The experimental results demonstrate that this unit-cell exhibits a $3.8 \%$ bandwidth for a phase resolution better than 1.92 bits in LHCP and in RHCP.

\section{REFERENCES}

[1] J. Huang and J. A. Encinar, "Reflectarray antennas", Wiley-IEEE Press, ISBN: 978-0-470-08491-5, Nov. 2007.

[2] L. Ren, Y. Jiao, F. Li, J. Zhao, and G. Zhao, "A dual-layer T-shaped element for broadband circularly polarizzed refelctarray with linearly polarized feed," IEEE Antennas Wireless Propag. Lett., vol. 10, pp. 407410, 2011.

[3] D. Pozar and T. Metzler, "Analysis of a reflectarray antenna using microstrip patches of variable size," Electronics Letters, vol. 29, Apr. 1993.

[4] M. Albooyeh and N. Komjani, "Circularly polarized element for reflectarray antennas”, IEEE Antennas Wireless Propag. Lett., vol. 8, pp. 319-322, 2009

[5] G. Zhao, Y. Jiao, F. Zhang and F. Zhang, "A subwavelength element for broadband circularly polarized reflectarrays," IEEE Antennas Wireless Propag. Lett., vol. 9, pp. 330-333, 2010.

[6] M. Zhao, G. Zhang, X. Lei, J. Wu and J. Shang, "Design of New SingleLayer Multiple-Resonance Broadband Circularly Polarized Reflectarrays", IEEE Antennas and Wireless Propagation Letters, vol. 12, pp. 356-359, 2013.

[7] A. E. Martynyuk and J. I. Martinez Lopez, "Reflective antenna arrays based on shorted ring slots," IEEE Microwave Symposium Digest, vol. 2, pp. 1379-1382, Phoenix (AZ), May 2001.

[8] A. Yu, F. Yang, A. Z. Elsherbeni, and J. Huang, "An X-band circularly polarized reflectarray using split square ring elements and the modified element rotation technique," IEEE Antennas and Propag. Soc. Int. Symp. San Diego (California), Jul. 2008.

[9] A.Yu, F. Yang, A. Z. Elsherbeni, and J. Huang, "Design and measurement of a circularly polarized Ka-band reflectarray antenna," Proceedings of the $3^{\text {rd }}$ European Conference Antennas and Propag., Berlin, Germany, 23-27 Mar. 2009.

[10] S. Malfajani and Z. Atlasbaf, "Design and implementation of a broadband single layer circularly polarized reflectarray antenna," IEEE Antennas Wireless Propag. Lett., vol. 11, pp. 973-976, 2012.

[11] B. Strassner, C. Han, and K. Chang, "Circularly polarized reflectarray with microstrip ring elements having variable rotation angles," IEEE Trans. Antennas Propag., vol. 52, no. 4, pp. 1122-1125, Apr. 2004.

[12] C. Han, C. Rodenbeck, J. Huang, and K. Chang, "A C/Ka dual frequency dual layer circularly polarized reflectarray antenna with microstrip ring elements," IEEE Trans. Antennas Propag., vol. 52, no. 11, pp. 28712876, Nov. 2004.
[13] J. Huang, C. Han, and K. Chang, "A Cassegrain offset-fed dual-band reflectarray," IEEE Antennas Propag. Soc. Int. Symp., Albuquerque (New Mexico), pp. 2439-2442, Jul. 2006.

[14] A. Yu, F. Yang, A. Z. Elsherbeni, and J. Huang, "Experimental demonstration of a single layer tri-band circularly polarized reflectarray,' IEEE Antennas Propag. Soc. Int. Symp., Toronto, Canada, 11-17 Jul. 2010.

[15] C. Guclu, J. Perruisseau-Carrier, and O. A. Civi, "Proof of concept of a dual-band circularly-polarized RF MEMS beam-switching reflectarray," IEEE Trans. Antennas Propag., vol. 60, no. 11, pp. 5451-5455, Nov. 2012.

[16] H. Phelan, "Spira-phase, a new low cost, lightweight phased array," Microwave journal, pp. 41-44, Dec. 1976.

[17] A. E. Martynyuk, J. I. Martinez Lopez, and N. A. Martynyuk, "Reflectarray based on three-bit spatial phase shifters: mathematical model and technology of fabrication," Proceedings of the $3^{\text {rd }}$ European Conference Antennas and Propag., Berlin, Germany, 23-27 Mar. 2009.

[18] A. E. Martynyuk, J. I. Martinez Lopez, and N. A. Martynyuk, "Spiralphase-type reflectarrays based on loaded ring slot resonators," IEEE Trans. Antennas Propag., vol. 52, no. 1, pp. 142-153, Jan. 2004.

[19] S. Mener, R. Gillard, R. Sauleau, C. Cheymol, and P. Potier, "Design and characterization of a CPSS-based unit-cell for circularly-polarized reflectarray applications," IEEE Trans. Antennas Propag, vol. 61, no. 4, pp. 2313-2318, Apr. 2013.

[20] S. Mener, R. Gillard, R. Sauleau, C. Cheymol, and P. Potier, "A CPSSbased reflectarray cell with reconfigurable capabilities," Proceedings of the $6^{\text {th }}$ European Conference Antennas and Propag., Prague, Czech Republic, 26-30 Mar. 2012.

[21] S. Mener, R. Gillard, R. Sauleau, C. Cheymol, and P. Potier, "Design of a CPSS-based reflectarray cell with controllable reflected phase for dual circularly polarized reflectarrays," Proceedings of the Intern. Symp. on Antenna Technology and Applied Electromagnetics, ANTEM 2012, Toulouse, France, 25-28 Jun. 2012.

[22] E. Girard, R. Moulinet, R. Gillard and H. Legay, "An FDTD optimization of a circularly polarized reflectarray unit cell," IEEE Antennas Propag. Soc. Int. Symposium, San Antonio (TX), vol. 3, pp. 136-139, Jun. 2002.

[23] R. Pierrot, "Éléments résonnants en polarisation circulaire et réflecteur semi-transparent composé de ces éléments," French patent 89.609, no. $1.512 .598,1966$

[24] R. Pereira, R. Gillard, R. Sauleau, P. Potier, T. Dousset, and X. Delestre, "Dual linearly-polarized unit-cells with nearly 2-bit resolution for reflectarray applications in X-band," IEEE Trans. Antennas Propagat., vol. 60, no. 12, pp. 6042-6048, Dec 2012.

[25] C. Cheymol, T. Dousset, P. Dumon, M. Labeyrie, and C. Renard, "A Xband electronically scanned reflectarray antenna for space telemetry," Proceedings of the $3^{\text {rd }}$ European Conference Antennas and Propag., Berlin, Germany, 23-27 Mar. 2009.

[26] S. Mener, R. Gillard, R. Sauleau, C. Cheymol, and P. Potier, "An improved topology for reconfigurable CPSS-based reflectarray cell," Proceedings of the $7^{\text {th }}$ European Conference Antennas and Propag., Gothenburg, Sweden, 8-12 Apr. 2013.

[27] A. Capozzoli, C. Curcio, G. D'Elia, A. Liseno, D. Bresciani, and H. Legay, "Fast phase-only synthesis of faceted reflectarrays," Proceedings of the ${ }^{3 r d}$ European Conference Antennas and Propag., Berlin, Germany, 23-27 Mar. 2009

[28] J. Roy, "A new CPSS element," IEEE Antennas Propag. Soc. Int. Symp. Chicago (OH), Jul. 8-14, 2012.

[29] J. Huang and R. J. Pogorzelski, "A Ka-band microstrip reflectarray with elements having variable rotation angles," IEEE Trans. Antennas Propag, vol. 46, no. 5, pp. 650-656, May 1998. 